\title{
Indicadores para a gestão de resíduos sólidos em aeroportos e sua aplicação no Aeroporto Internacional de Viracopos, Campinas, São Paulo
}

\section{Indicators for solid waste management in airports and their application at Viracopos International Airport, Campinas, São Paulo, Brazil}

\section{Thales Andrés Carra}

Engenheiro Ambiental pela Universidade Estadual Paulista "Júlio de Mesquita Filho" (UNESP). Mestre em Geologia Regional pelo Instituto de Geociências e Ciências Exatas (IGCE) da UNESP - Rio Claro (SP), Brasil.

\section{Fabiano Tomazini da Conceição}

Geólogo pela Universidade Estadual Paulista "Júlio de Mesquita Filho" (UNESP). Mestre em Geociências. Doutor em Geologia Regional pelo Instituto de Geociências e Ciências Exatas (IGCE) da UNESP. Professor adjunto I da UNESP - Rio Claro (SP), Brasil.

\section{Bruno Bernardes Teixeira}

Engenheiro Ambiental pela Universidade de São Paulo (USP). Mestrando em Engenharia Civil, Arquitetura e Urbanismo pela Universidade Estadual de Campinas (UNICAMP) - Campinas (SP), Brasil.

\section{Resumo}

Considerando o contexto atual de valorização da questão ambiental, os objetivos deste trabalho foram propor e aplicar indicadores para avaliar o gerenciamento de resíduos sólidos em aeroportos. Para tanto, foram elaborados 17 indicadores sobre geração, armazenamento, transporte, coleta e destinação de resíduos sólidos. Estes foram aplicados no Aeroporto Internacional de Viracopos, em Campinas, no estado de São Paulo. Os resultados obtidos no estudo apresentaram desempenho de 2,9, em uma escala de um a cinco, caracterizado como regular. Posteriormente, foram analisadas as principais fragilidades no gerenciamento dos resíduos no Aeroporto Internacional de Viracopos, bem como a identificação de boas práticas e soluções ambientais para o desenvolvimento das atividades do empreendimento. Dentre as estratégias de manejo sugeridas, destacam-se a adequação de áreas para armazenamento de resíduos, a implantação de coleta seletiva e a realização de compostagem.

Palavras-chave: resíduos sólidos; aeroportos; gerenciamento ambiental.

\begin{abstract}
Taking into account the current context about environmental concern, the main purposes of this research were to develop and apply indicators in order to evaluate waste residues management in airports. As a result, 17 indicators related to generation, storage, transportation, collection, and solid waste disposal were created. These were applied in Viracopos International Airport, in Campinas, São Paulo State, Brazil. The results obtained in the study had a 2.9 performance, in a scale from one to five, characterized as regular. Posteriorly, the main weaknesses in waste residues management were analyzed in such Airport, as well as good practices and solutions were identified. The highlighted management strategies suggested were the adjustment of areas for waste storage, recycling and residues composting
\end{abstract}

Keywords: waste residues; airports; environmental management. 


\section{Introdução}

Entende-se por resíduo aeroportuário, que é também denominado de resíduo de serviços de transportes (BRASIL, 2010), todo aquele sólido ou semissólido que resulta de atividades específicas de origens diversas (industrial, doméstica, hospitalar, comercial, agrícola, de serviços e varrição), desenvolvidas dentro das fronteiras dos aeroportos ou a bordo de aeronaves que a eles se destinam (OACI, 1996). De maneira análoga à Norma Brasileira (NBR) 10.004/2004, ficam incluídos nesta definição os lodos provenientes dos sistemas de tratamento de esgoto e aqueles gerados em equipamentos e instalações para controlar poluição.

Por ser um ponto no qual, além da passagem, ocorre o armazenamento de resíduos oriundos de áreas distantes e exóticas, os aeroportos configuram-se como locais estratégicos dos pontos de vista sanitário e ambiental (CORDEIRO; BARBOSA; DUARTE, 2000). Assim, o gerenciamento de resíduos sólidos em aeroportos possui grande complexidade e, se não for bem realizado, pode gerar diversos impactos negativos, tais como a contaminação do solo e da água, a veiculação de doenças e os elevados custos para reversão dos problemas.

Segundo Pitt, Brown e Smith (2002), alguns aeroportos produzem volumes de resíduos equivalentes a pequenas cidades, causando significantes impactos nas regiões em que estão situados. Entretanto, a questão do gerenciamento de resíduos sólidos em aeroportos tem tido pouco destaque quando comparada a outros temas como emissões atmosféricas e ruído, encontrando-se poucos autores que abordam o assunto dentro e fora do Brasil.

No entanto, a legislação brasileira dispõe de um conjunto de resoluções e normas que tratam sobre o assunto, com destaques para a Resolução do Conselho Nacional de Meio Ambiente (CONAMA) 05/1993; a Resolução de Diretoria Colegiada da Agência Nacional de Vigilância Sanitária (ANVISA) 56/2008 e a NBR 8.843 (ABNT, 1996), que fornecem diretrizes sobre as boas práticas no gerenciamento de resíduos sólidos em tais locais. Ambas as resoluções fornecem diretrizes mínimas para cada etapa do gerenciamento dos resíduos sólidos em aeroportos e incluem as obrigações e os responsáveis pelo cumprimento das disposições previstas nesses regulamentos. Desse modo, os resíduos aeroportuários são classificados em cinco grupos, conforme os riscos gerados e o respectivo tipo/local de geração, a saber:

- Grupo A: apresentam risco biológico (gerado a bordo de aeronaves, ambulatórios e terminais de carga);

- Grupo B: apresentam risco químico (gerado em áreas industriais e de manobras, como óleos, lâmpadas de mercúrio e baterias);

- Grupo C: materiais radioativos ou contaminados com radioisótopos;

- Grupo D: resíduo comum;

- Grupo E: perfurocortante (lâminas, agulhas, ampolas de vidro e escalpes).

Para aeroportos internacionais com trânsito de passageiros e/ou cargas, o Ministério da Agricultura, Pecuária e Abastecimento por meio da
Vigilância Agropecuária Internacional, também realiza a regulamentação e a fiscalização do gerenciamento de resíduos com vistas à redução dos riscos zoossanitários e fitossanitários. Como exemplo, o Manual de Procedimentos Operacionais da Vigilância Agropecuária Internacional, anexo da Instrução Normativa 36/2006 deste Ministério, estabelece a obrigatoriedade de tratamento em zona primária (ou seja, no interior do sítio aeroportuário) dos resíduos orgânicos a bordo de aeronaves no trânsito internacional (BRASIL, 2006).

Dentre as obrigações impostas pelos órgãos de meio ambiente e saúde aos administradores de aeroportos, inclui-se a elaboração de um plano de gerenciamento de resíduos sólidos (PGRS). Este tem como objetivo apontar e descrever ações relativas ao manejo de resíduos sólidos, contemplando os aspectos referentes a todas as etapas da gestão dos resíduos, desde a geração até a disposição final. Diante deste cenário e considerando o contexto atual de preservação ambiental, a complexidade no gerenciamento de resíduos em aeroportos requer que qualquer instância da administração aeroportuária não negligencie essa questão.

Dessa maneira, surge a necessidade da administração aeroportuária e das partes interessadas serem alertadas quanto aos diferentes aspectos ambientais associados à gestão dos resíduos sólidos nos aeroportos, para que possam atuar pronta e objetivamente no controle e na minimização de seus impactos. Neste contexto, o uso de indicadores torna-se um instrumento que auxilia a administração aeroportuária a identificar os aspectos ambientais significativos e as oportunidades a fim de melhorar a gestão dos resíduos, possibilitando a apresentação desses resultados de maneira acessível ao público e aos responsáveis pelas tomadas de decisão.

Por meio dos indicadores, pode-se então coletar os dados para avaliar o status do desempenho da gestão dos resíduos sólidos e identificar onde as melhorias são necessárias. Entretanto, a grande dificuldade em se avaliar o desempenho na gestão dos resíduos em um aeroporto constitui-se na elaboração dos indicadores, na indisponibilidade de dados para comparação com outras empresas e na dificuldade em se obter um desempenho global. Portanto, o presente estudo teve como objetivo desenvolver indicadores para avaliar o desempenho da gestão de resíduos sólidos em aeroportos e aplicá-la no Aeroporto Internacional de Viracopos, Campinas, São Paulo, bem como propor medidas para a melhora contínua deste empreendimento.

\section{Aspectos gerais do Aeroporto Internacional de Viracopos}

Localizado a aproximadamente $18 \mathrm{~km}$ do centro de Campinas e a $95 \mathrm{~km}$ do centro de São Paulo, o Aeroporto Internacional de Viracopos, Campinas, no estado de São Paulo, foi fundado em 1930, a partir da construção de uma pista de pouso rudimentar utilizada pelos paulistas na Revolução de 1932 (WALM, 2008). Segundo o Plano 
Diretor do Município de Campinas, o aeroporto localiza-se na chamada Macrozona 7, intitulada "Área de Influência Aeroportuária (AIA)", ilustrada na Figura 1. Esse local inclui tanto o aeroporto como sua área de expansão, além dos bairros do seu entorno e está sujeito aos impactos das operações aeroportuárias. Parte dessas áreas é caracterizada como rural e apresenta infraestrutura urbana precária, reduzido potencial para expandir o saneamento básico, restrições ambientais para captação na Bacia do Rio Capivari-Mirim, onde o aeroporto está inserido, e sistema viário descontínuo (STRUCHEL; CAPPA; BERNARDO, 2008).

Após diversas obras e instalações de equipamentos, o Aeroporto de Viracopos foi homologado para operações internacionais em 1960. Desde 1995, a Empresa Brasileira de Infraestrutura Aeroportuária (INFRAERO) realiza investimentos para melhorias nos terminais de cargas e passageiros. A primeira fase foi inaugurada no primeiro semestre de 2004, quando o aeroporto passou a contar com novas salas de embarques, desembarques, áreas públicas e concessões comerciais. Em 2005, foi entregue a ampliação do terminal de passageiros. Como resultado dos investimentos e considerando o esgotamento da capacidade do Aeroporto de São Paulo/Congonhas e do Aeroporto Internacional de São Paulo/Guarulhos, em dezembro de 2008, Viracopos passou a operar mais voos de passageiros, o que alavancou o número de embarques, quintuplicando a quantidade de passageiros embarcados de 2008 a 2010.

Atualmente, em termos nacionais, o Aeroporto Internacional de Viracopos é o $12^{\circ}$ em embarque de passageiros, o segundo em movimentação de cargas e o primeiro em valor agregado, o que faz com que assuma grande importância na cadeia de produção da Região Metropolitana de Campinas (INFRAERO, 2011). Além disso, as projeções do Plano Diretor do aeroporto colocam Viracopos como o maior da América Latina, com previsão para o atendimento de 50 milhões de passageiros e 2,3 milhões de toneladas de carga até 2025, ou seja, aproximadamente dez vezes a mais o movimento de 2010 (WALM, 2008).

Com relação aos recursos hídricos, o Aeroporto Internacional de Viracopos está inserido na bacia do Rio Capivari-Mirim, integrante da Unidade de Gerenciamento de Recursos Hídricos no 5 Piracicaba/Capivari/Jundiaí (PCJ), reunindo as Bacias Hidrográficas dos rios Piracicaba, Capivari e Jundiaí. A bacia do Rio Capivari, com aproximadamente $180 \mathrm{~km}$ de extensão, situa-se na margem direita do Rio Tietê, sendo os rios Capivari e Capivari-Mirim seus principais cursos d'água. Sua área é caracterizada pela intensa ocupação por atividades antrópicas, com predomínio do cultivo da cana-de-açúcar (40\% da área), seguido pelas pastagens, pelo cultivo de milho, café e feijão, além da ocorrência de reflorestamentos e atividades hortifrutigranjeiras (STRUCHEL et al., 2008). São significativas as áreas urbanas densamente ocupadas, existentes a montante da área do empreendimento. Os principais usos da água são para os abastecimentos público e industrial e respectivo afastamento de efluentes e irrigação de plantações. A área do aeroporto é atravessada, em sua porção central, pelo Córrego Ribeirão Viracopos que deságua na margem esquerda do Rio Capivari-Mirim.

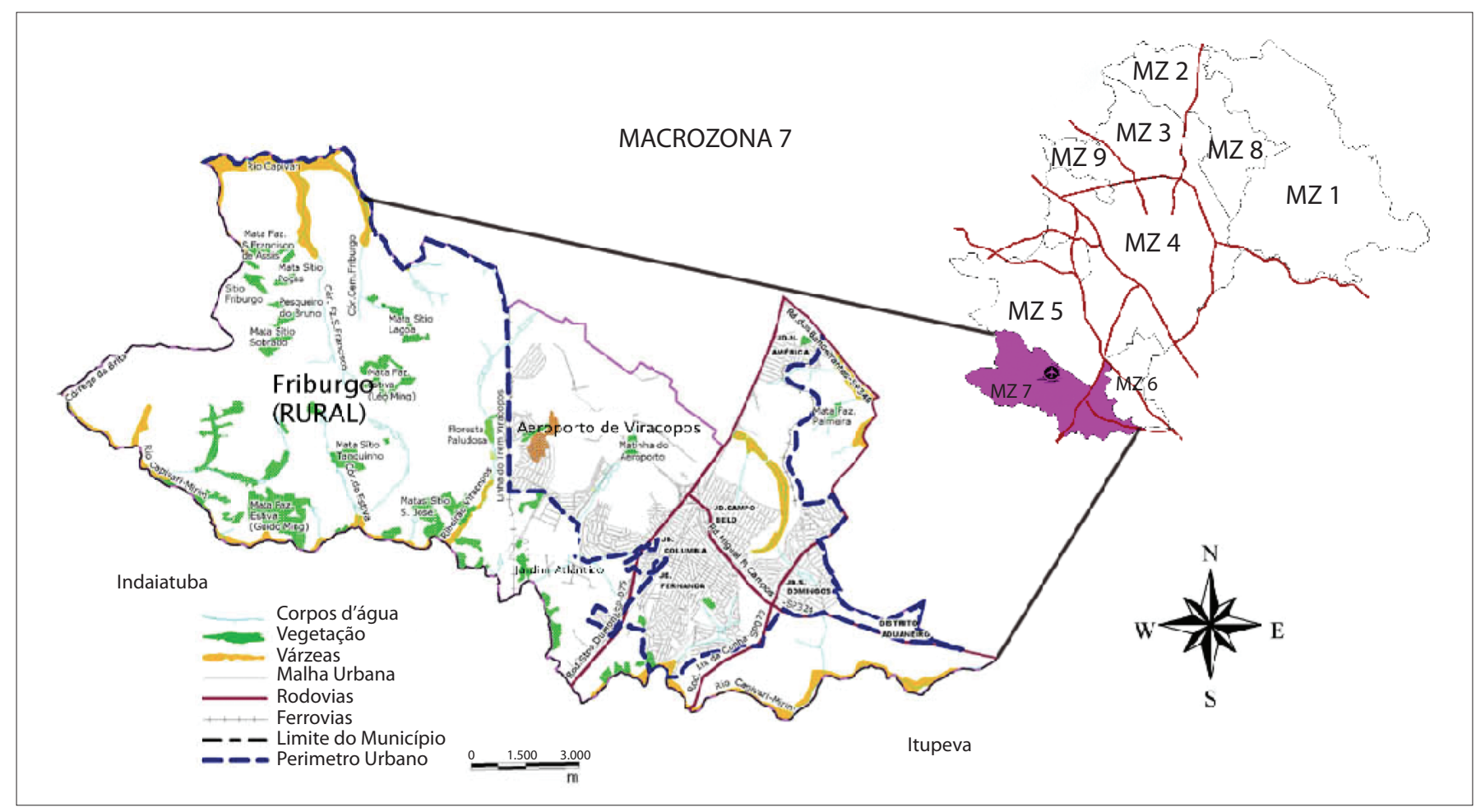

Figura 1 - Área de influência aeroportuária, Macrozona 7 (CAMPINAS, 2006). 
Sobre o gerenciamento de resíduos sólidos, em 2010, foram geradas aproximadamente 100 toneladas, por mês, no Aeroporto Internacional de Viracopos, das quais aproximadamente 97\% da massa correspondem aos resíduos dos Grupos A e D, gerados principalmente nos terminais de passageiros e cargas e pelas companhias aéreas a bordo das aeronaves (INFRAERO, 2011). Dos resíduos perigosos gerados no aeroporto, destaca-se o grande volume daqueles infectantes em 2010, ou seja, aproximadamente 3,8 toneladas. mês ${ }^{-1}$. Deste total, 55\% são provenientes da forração de baia do terminal de cargas vivas e 44\% são resíduos de bordo de aeronaves, sendo o restante gerado no ambulatório médico do terminal de passageiros. No que diz respeito aos resíduos com risco químico, em 2010, destaca-se a geração de aproximadamente 540 unidades por mês de lâmpadas fluorescentes inservíveis e 0,830 toneladas. ês $^{-1}$ de baterias tracionárias utilizadas em empilhadeiras. As quantidades de resíduos de áreas verdes e construção civil não foram estimadas neste aeroporto.

\section{Materiais e métodos}

Para a gestão dos resíduos sólidos de um aeroporto, este trabalho propôs uma metodologia baseada na NBR 14.031/2004 e na metodologia do Carbono Social ${ }^{\mathrm{TM}}$ - Social Carbon (REZENDE \& MERLIN, 2003; SANTOS, 2008). Dessa maneira, esta se baseia na elaboração e na aplicação de indicadores que priorizam os critérios ambientais e tem como avaliação o gerenciamento de resíduos sólidos. Sua descrição e aplicação foram desenvolvidas em quatro etapas, seguindo o modelo gerencial PDCA (Plan - Planejar, Do - Fazer, Check - Checar e Act - Agir) para avaliação de desempenho ambiental (ADA), como ilustrado na Figura 2.

A primeira etapa (planejar) consistiu em selecionar e elaborar os indicadores com base no levantamento dos principais aspectos relacionados ao gerenciamento de resíduos sólidos em aeroportos. Para isso,

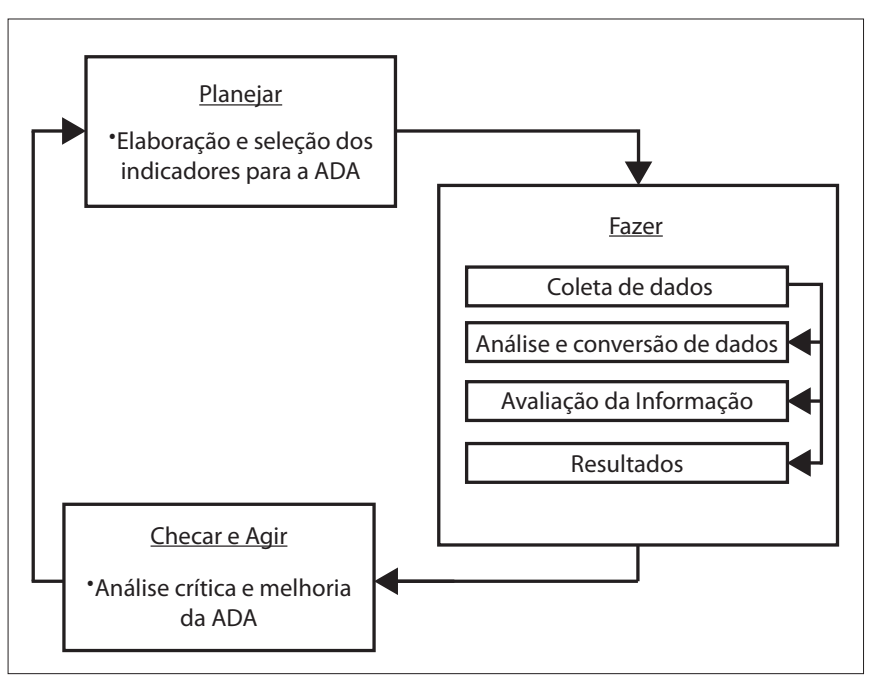

Figura 2 - Etapas para avaliação de desempenho ambiental - ADA (ABNT, 2004). realizou-se um levantamento bibliográfico sobre o assunto, seguido de consultas a documentos técnicos como manuais, normas, planos e programas ambientais em aeroportos brasileiros. Com base nos dados bibliográficos levantados, foram criados indicadores para representar cinco condições que recebem uma pontuação desde o pior cenário até a condição ideal. Assim, o desempenho caracterizado como ruim recebe o índice "1"; crítico, "2"; regular, "3"; satisfatório, "4"; e bom, "5". Tais indicadores foram elaborados considerando os desempenhos gerencial e operacional da organização, bem como a condição ambiental do aeroporto relacionada ao gerenciamento dos resíduos sólidos. Dessa maneira, eles abordam diferentes possíveis cenários sobre geração, armazenamento, transporte, coleta, tratamento e destinação dos resíduos sólidos, considerando os diferentes tipos e grupos de resíduos, além do esforço organizacional para o correto gerenciamento e para a mitigação do impacto ambiental associado.

Na segunda etapa (fazer) houve a aplicação da ADA no Aeroporto Internacional de Viracopos, por meio do levantamento das informações para aplicar indicadores pela coleta de dados em entrevistas e visitas de campo. Esta etapa contemplou ainda a conversão dos dados obtidos, comparando-se a característica apresentada pelo empreendimento com os possíveis cinco cenários para cada indicador. O cenário que apresentou maior semelhança com a característica do indicador foi selecionado e seu respectivo índice, atribuído. Os indicadores e respectivos cenários propostos são apresentados na Tabela 1 .

$\mathrm{Na}$ terceira e na quarta etapas (checar e agir) foram analisadas as principais fragilidades no gerenciamento dos resíduos no Aeroporto Internacional de Viracopos. Para isso, adotou-se o modelo de pressão-estado-resposta (OECD, 2001), que se baseia em três frentes: a pressão do homem, o estado do meio e a resposta da sociedade, servindo para identificar os prováveis impactos ambientais e definir as estratégias de manejo, de maneira a estabelecer boas práticas ambientais para o aeroporto analisado.

\section{Resultados e discussão}

Com base nos resultados do levantamento dos atuais procedimentos para gerenciamento de resíduos sólidos no Aeroporto Internacional de Viracopos, foi possível atribuir os índices aos indicadores propostos neste trabalho, os quais são apresentados na Tabela 1 .

Como se pode observar pelos valores dos índices atribuídos apresentados na Tabela 1, o desempenho ambiental do aeroporto em relação ao gerenciamento de resíduos sólidos pode ser considerado regular, pois obteve média aritmética de 2,9. Embora o tema em questão não apresente indicadores com desempenho bom, 76\% deles mostraram índices regular ou satisfatório. As variáveis que apresentaram melhor desempenho são relacionadas à redução na geração, coleta e transporte de resíduos sólidos. Por outro lado, aquelas referentes à coleta seletiva solidária, lâmpadas inservíveis, resíduos de áreas verdes e da construção civil apresentaram os piores desempenhos. 
Tabela 1 - Indicadores e resultados para avaliação do gerenciamento de resíduos sólidos no Aeroporto Internacional de Viracopos.

\begin{tabular}{|c|c|c|c|c|c|c|}
\hline \multirow{2}{*}{ Indicador } & \multirow{2}{*}{$\begin{array}{l}\text { Índice } \\
\text { atribuído }\end{array}$} & \multicolumn{5}{|c|}{ Índice } \\
\hline & & 1 & 2 & 3 & 4 & 5 \\
\hline $\begin{array}{l}\text { Plano de ge- } \\
\text { renciamento de } \\
\text { resíduos sólidos }\end{array}$ & 3 & $\begin{array}{l}\text { O aeroporto não } \\
\text { dispõe de um PGRS }\end{array}$ & $\begin{array}{l}\text { O aeroporto dispõe } \\
\text { de um PGRS sem } \\
\text { atualização há mais } \\
\text { de cinco anos }\end{array}$ & $\begin{array}{l}\text { O aeroporto dispõe } \\
\text { de um PGRS atuali- } \\
\text { zado por menos de } \\
\text { cinco anos; no entan- } \\
\text { to, menos da metade } \\
\text { das ações propostas } \\
\text { foram executadas }\end{array}$ & $\begin{array}{l}\text { O aeroporto dispõe de } \\
\text { um PGRS atualizado há } \\
\text { menos de cinco anos } \\
\text { e mais da metade das } \\
\text { ações propostas foram } \\
\text { executadas }\end{array}$ & $\begin{array}{l}\text { O aeroporto dispõe de } \\
\text { um PGRS atualizado há } \\
\text { menos de cinco anos e } \\
\text { todas as ações propostas } \\
\text { foram executadas }\end{array}$ \\
\hline
\end{tabular}

\begin{tabular}{|c|c|c|}
\hline $\begin{array}{l}\text { Redução da } \\
\text { geração de resí- } \\
\text { duos sólidos }{ }^{1}\end{array}$ & 4 & $I R S \geq 1,5$ \\
\hline $\begin{array}{l}\text { Armazenamento } \\
\text { de resíduos dos } \\
\text { Grupos A e D }\end{array}$ & 3 & $\begin{array}{l}\text { O aeroporto não } \\
\text { possui contêineres } \\
\text { para armazenamen- } \\
\text { to de resíduos, que } \\
\text { ficam diretamente } \\
\text { sobre o solo }\end{array}$ \\
\hline
\end{tabular}

$$
1<\mathrm{IRS}<1,5
$$

$$
\mathrm{IRS}=1
$$

$$
0,5<\operatorname{IRS}<1
$$$$
\mathrm{IRS} \leq 0,5
$$

$\begin{array}{lll}\begin{array}{l}\text { Contaminação } \\ \text { cruzada }\end{array} & 3 & \begin{array}{l}\text { Os resíduos peri- } \\ \text { gosos não são segre- } \\ \text { gados dos demais }\end{array}\end{array}$

\section{Os recipientes são}

Higienização dos contêineres (Grupo A e D) 3 a um mês e não há tratamento para o efluente gerado no processo

A coleta dos resíduos

Coleta (comum 4 é realizada em período superior a dois dias
Os resíduos são armazenados em contêineres, mas a disposição é direta no solo, em local descoberto ou sem impermeabilização
Os resíduos são armazenados em contêineres, mas a disposição não é direta no solo, mas em local descoberto ou sem impermeabilização

Os resíduos perigosos Os resíduos perigosão segregados dos sos são segregados demais, mas há evi- dos demais, mas há dências de contamina- risco aparente de ção cruzada contaminação

Os recipientes são Os recipientes higienizados em perío- são higienizados dos superiores a um mês e há tratamento para o efluente gerado no processo

\section{mensalmente e há} tratamento para o efluente gerado no processo

A coleta dos resíduos é realizada a cada dois dias

A coleta dos resíduos é realizada uma vez por dia

Os resíduos não recebem tratamento

Tratamento dos resíduos de bordo (Grupo A)

3 e são dispostos em aterros sanitários para resíduos comuns

O transporte interno atravessa locais que não são permitidos

Transporte de resíduos

4 pela ANVISA e o transporte externo não é realizado com veículos específicos

Não há segregação de materiais reciclá-

Resíduos comuns

4 veis e os resíduos comuns são enviados a lixões ou dispostos irregularmente

Os materiais recicláveis gerados no

Coleta seletiva solidária

2 aeroporto não são segregados dos demais

Os resíduos ficam

Resíduos contendo óleos, tintas e lubrificantes armazenados em locais sem cobertura e contenção, sendo destinados de forma inadequada
Os resíduos não recebem tratamento e são dispostos em aterros sanitários para resíduos perigosos

O transporte interno atravessa locais que não são permitidos pela ANVISA e o transporte externo é realizado com veículos específicos

Não há segregação de materiais recicláveis e os resíduos comuns são destinados para aterro em vala

Menos de $30 \%$ dos materiais recicláveis segregados no aeroporto são destinados a associações ou cooperativas

Os resíduos ficam armazenados em locais sem cobertura e contenção, mas são destinados a empresas especializadas no tratamento ou destinação
Os resíduos recebem tratamento, mas não é previsto pelo MAPA e pela ANVISA

O transporte interno atravessa locais permitidos pela ANVISA e o transporte externo não é realizado com veículos específicos

Não há segregação de materiais recicláveis e os resíduos comuns são destinados para aterros sanitários

De 30 a $50 \%$ dos materiais recicláveis segregados no aeroporto são destinados a associações ou cooperativas

Os resíduos ficam armazenados em locais cobertos e com contenção por mais de 30 dias, sendo destinados a empresas especializadas no tratamento ou destinação o tipo de tratamento
Os resíduos são armazenados em contêineres, o local é coberto e possui impermeabilização

Os resíduos perigosos são segregados dos demais e não há risco aparente de contaminação cruzada

Os recipientes são higienizados quinzenalmente e há tratamento para o efluente gerado no processo

A coleta dos resíduos é realizada duas vezes por dia

Os resíduos recebem tratamento previsto pelo MAPA e pela ANVISA, mas ocorre em zona secundária

O transporte interno atravessa locais permitidos pela ANVISA e o transporte externo é realizado com veículos específicos

Há segregação dos materiais recicláveis e os resíduos comuns são destinados para aterros sanitários

Entre 51 a $70 \%$ dos ma- Mais de $70 \%$ dos mateteriais recicláveis segre- riais recicláveis segregados no aeroporto são destinados a associações ou cooperativas destinados a associações

Os resíduos ficam armazenados em locais cobertos e com contenção de 15 a 30 dias, sendo destinados a empresas especializadas no tratamento ou destinação gados no aeroporto são ou cooperativas

Os resíduos são armazenados em contêineres, o local é coberto, possui impermeabilização e sistema para limpeza

Os resíduos perigosos são segregados e armazenados em ambientes separados e não há risco aparente de contaminação cruzada

Os recipientes são higienizados semanalmente e há tratamento para o efluente gerado no processo

A coleta dos resíduos é realizada mais de duas vezes por dia

Os resíduos recebem tratamento previsto pelo MAPA e pela ANVISA em zona primária

O transporte interno atravessa locais permitidos pela ANVISA e o transporte externo é realizado com veículos específicos por sistemas automatizados de coleta

Há segregação dos materiais recicláveis e os resíduos comuns são destinados aos sistemas de reaproveitamento ou cooperativas

Os resíduos ficam armazenados em locais cobertos e com contenção por menos de 15 dias, sendo destinados a empresas especializadas no tratamento ou destinação 
Tabela 1 - Continuação.

\begin{tabular}{|c|c|c|c|c|c|c|}
\hline \multirow{2}{*}{ Indicador } & \multirow{2}{*}{$\begin{array}{l}\text { Índice } \\
\text { atribuído }\end{array}$} & \multicolumn{5}{|c|}{ Índice } \\
\hline & & 1 & 2 & 3 & 4 & 5 \\
\hline $\begin{array}{l}\text { Pneus } \\
\text { inservíveis }\end{array}$ & 3 & $\begin{array}{l}\text { Os pneus não são } \\
\text { enviados para } \\
\text { reutilização ou reci- } \\
\text { clagem, mas ficam } \\
\text { armazenados por } \\
\text { períodos superiores } \\
\text { a } 12 \text { meses }\end{array}$ & $\begin{array}{l}\text { Os pneus são tritura- } \\
\text { dos e enviados para } \\
\text { aterros sanitários, mas } \\
\text { ficam armazenados em } \\
\text { períodos superiores a } \\
12 \text { meses }\end{array}$ & $\begin{array}{l}\text { Os pneus são envia- } \\
\text { dos para reutilização } \\
\text { ou reciclagem, mas } \\
\text { ficam armazenados } \\
\text { por períodos superio- } \\
\text { res a } 12 \text { meses }\end{array}$ & $\begin{array}{l}\text { Os pneus são enviados } \\
\text { para reciclagem e } \\
\text { ficam armazenados por } \\
\text { períodos inferiores a } 12 \\
\text { meses }\end{array}$ & $\begin{array}{l}\text { Os pneus são devolvidos } \\
\text { aos fabricantes e ficam ar- } \\
\text { mazenados em períodos } \\
\text { inferiores a seis meses }\end{array}$ \\
\hline $\begin{array}{l}\text { Lâmpadas } \\
\text { usadas }\end{array}$ & 2 & $\begin{array}{l}\text { As lâmpadas não } \\
\text { são enviadas para } \\
\text { reciclagem e ficam } \\
\text { armazenadas por } \\
\text { períodos superiores } \\
\text { a } 12 \text { meses }\end{array}$ & $\begin{array}{l}\text { As lâmpadas são envia- } \\
\text { das para reciclagem e } \\
\text { ficam armazenadas por } \\
\text { períodos superiores a } \\
12 \text { meses }\end{array}$ & $\begin{array}{l}\text { As lâmpadas são } \\
\text { enviadas para } \\
\text { reciclagem e ficam } \\
\text { armazenadas por } \\
\text { períodos inferiores a } \\
12 \text { meses }\end{array}$ & $\begin{array}{l}\text { As lâmpadas são envia- } \\
\text { das para reciclagem e } \\
\text { ficam armazenadas por } \\
\text { períodos inferiores a seis } \\
\text { meses }\end{array}$ & $\begin{array}{l}\text { As lâmpadas são devol- } \\
\text { vidas aos fabricantes e } \\
\text { ficam armazenadas em } \\
\text { períodos inferiores a seis } \\
\text { meses }\end{array}$ \\
\hline $\begin{array}{l}\text { Baterias } \\
\text { chumbo-ácido } \\
\text { inservíveis }\end{array}$ & 3 & $\begin{array}{l}\text { As baterias são } \\
\text { dispostas em lixões } \\
\text { ou não há controle } \\
\text { sobre o destino }\end{array}$ & $\begin{array}{l}\text { As baterias são dis- } \\
\text { postas em aterros de } \\
\text { resíduos comuns }\end{array}$ & $\begin{array}{l}\text { As baterias são desti- } \\
\text { nadas a aterros de } \\
\text { Classe I }\end{array}$ & $\begin{array}{l}\text { As baterias são desti- } \\
\text { nadas a reciclagem e } \\
\text { ficam armazenadas em } \\
\text { períodos superiores a } \\
\text { dois meses }\end{array}$ & $\begin{array}{l}\text { As baterias são desti- } \\
\text { nadas a reciclagem e } \\
\text { ficam armazenadas em } \\
\text { períodos inferiores a dois } \\
\text { meses }\end{array}$ \\
\hline $\begin{array}{l}\text { Resíduos de } \\
\text { áreas verdes }\end{array}$ & 1 & $\begin{array}{l}\text { A administração } \\
\text { aeroportuária dispõe } \\
\text { os resíduos em bota- } \\
\text {-foras no interior do } \\
\text { sítio aeroportuário }\end{array}$ & $\begin{array}{l}\text { A administração ae- } \\
\text { roportuária dispõe os } \\
\text { resíduos em valas }\end{array}$ & $\begin{array}{l}\text { A administração ae- } \\
\text { roportuária dispõe os } \\
\text { resíduos em aterros } \\
\text { sanitários }\end{array}$ & $\begin{array}{l}\text { A administração ae- } \\
\text { roportuária destina os } \\
\text { resíduos em usinas de } \\
\text { compostagem }\end{array}$ & $\begin{array}{l}\text { A administração aeropor- } \\
\text { tuária realiza composta- } \\
\text { gem dos resíduos em área } \\
\text { interna ao aeroporto }\end{array}$ \\
\hline $\begin{array}{l}\text { Resíduos da } \\
\text { Construção Civil }\end{array}$ & 2 & $\begin{array}{l}\text { O aeroporto } \\
\text { possui áreas com } \\
\text { disposição irregular, } \\
\text { próximas a corpos } \\
\text { d'águas }\end{array}$ & $\begin{array}{l}\text { O aeroporto possui } \\
\text { áreas com disposição } \\
\text { irregular, mas não há } \\
\text { indícios de degrada- } \\
\text { ção do solo ou água }\end{array}$ & $\begin{array}{l}\text { O aeroporto possui } \\
\text { áreas com armaze- } \\
\text { namento temporário } \\
\text { adequado, mas não } \\
\text { há segregação dos } \\
\text { resíduos }\end{array}$ & $\begin{array}{l}\text { O aeroporto possui } \\
\text { áreas com armazena- } \\
\text { mento temporário ade- } \\
\text { quado, há segregação e } \\
\text { reciclagem, mas não há } \\
\text { reutilização interna dos } \\
\text { resíduos }\end{array}$ & $\begin{array}{l}\text { O aeroporto possui áreas } \\
\text { com armazenamento } \\
\text { temporário adequado, há } \\
\text { segregação, reciclagem } \\
\text { e reutilização interna dos } \\
\text { resíduos }\end{array}$ \\
\hline $\begin{array}{l}\text { Disposição em } \\
\text { bota-fora }\end{array}$ & 2 & $\begin{array}{l}\text { Ocorreu disposição } \\
\text { de resíduos em } \\
\text { áreas de bota-fora } \\
\text { no interior do sítio } \\
\text { aeroportuário e o } \\
\text { passivo encontra-se } \\
\text { no local }\end{array}$ & $\begin{array}{l}\text { Ocorreu disposição de } \\
\text { resíduos em áreas de } \\
\text { bota-fora no interior } \\
\text { do sítio aeroportuário, } \\
\text { mas o passivo foi } \\
\text { retirado do local e não } \\
\text { recebeu tratamento }\end{array}$ & $\begin{array}{l}\text { Ocorreu disposição } \\
\text { de resíduos em áreas } \\
\text { de bota-fora no inte- } \\
\text { rior do sítio aeropor- } \\
\text { tuário, mas o passivo } \\
\text { foi retirado do local e } \\
\text { recebeu tratamento }\end{array}$ & $\begin{array}{l}\text { Não ocorreu disposição } \\
\text { de resíduos em áreas } \\
\text { de bota-fora no interior } \\
\text { do sítio aeroportuário, } \\
\text { mas passivos anteriores } \\
\text { encontram-se no local }\end{array}$ & $\begin{array}{l}\text { O aeroporto não dispõe } \\
\text { de áreas de bota-fora em } \\
\text { toda área patrimonial }\end{array}$ \\
\hline Índice médio & 2,9 & & & & & \\
\hline
\end{tabular}

IRS: geração média de resíduos/número de movimentos de aeronaves do período analisado; geração média de resíduos/número de movimentos de aeronaves do período anterior.

Com o objetivo de avaliar qualitativamente e quantitativamente os resíduos gerados, o Aeroporto Internacional de Viracopos atualizou, no início de 2011, seu PGRS. Os resultados quantitativos da geração de resíduos apontaram um aumento de 57\% da massa total gerada em 2010, em relação a 2009. Entretanto, quando relacionada com o movimento de aeronaves, a quantidade de resíduos decresceu 9,6\% em relação ao mesmo período.

Quanto ao armazenamento intermediário dos resíduos dos Grupos A e D (infectante e comum, respectivamente), evidenciou-se a presença de contêineres específicos para cada um dos dois grupos (branco e verde para os Grupos A e D, respectivamente), e não foi observada disposição direta sobre o solo. Entretanto, no local onde ocorre a segregação dos resíduos de bordo de aeronave, foi possível identificar falta de cobertura e impermeabilização do piso. No mesmo ponto, os contêineres para resíduos infectantes e comuns são alocados sem separação física por paredes ou distâncias suficientes para que o risco de contaminação cruzada seja minimizado.
A higienização de tais recipientes é realizada a cada 30 dias. A lavagem é feita por meio de um lavador de contentores móvel, instalado sobre um caminhão. Essa operação acontece no interior de uma câmara fechada do lavador de contentor, por meio de água e alta pressão aditivada com produtos desengordurantes e bactericidas. Nesse procedimento, os resíduos sólidos ficam em uma câmara fechada no próprio caminhão e, posteriormente, são retirados e encaminhados ao aterro sanitário. O efluente é despejado na estação de tratamento de esgoto do aeroporto.

A coleta dos resíduos, após o armazenamento intermediário, é realizada três vezes ao dia. Após tal processo, os infectantes são enviados para tratamento térmico, pela técnica de micro-ondas, em zona secundária (área externa ao aeroporto). Segundo o Ministério da Agricultura, Pecuária e Abastecimento são admitidos três tipos de tratamento para os resíduos de bordo de aeronaves: incineração, autoclavagem $\left(133^{\circ} \mathrm{C}\right.$ com 3 bar por 20 minutos) e hidrólise alcalina (BRASIL, 2006). Atualmente, o Aeroporto Internacional de Viracopos dispõe de uma autoclave, mas o equipamento ainda não foi licenciado e o local de instalação necessita 
de adequações, como instalações elétricas e reforma do piso e das paredes. Dessa maneira, embora os resíduos de bordo de aeronave e outros infectantes recebam tratamento, o procedimento não é realizado no local e por meio de técnicas previstas por este Ministério.

Para a efetivação da coleta, os transportes interno e externo dos resíduos sólidos são feitos por veículos específicos, passando apenas por locais autorizados pela ANVISA. Os resíduos sólidos de bordo são transportados das aeronaves até os pontos de armazenamento intermediário por meio de veículo de apoio à aeronave. Aos resíduos infectantes, a coleta do ponto de armazenamento intermediário até o tratamento é realizada por um veículo adaptado, com carroceria fechada, devidamente identificada com a simbologia de infectante. Com relação aos resíduos comuns, o transporte é feito em um caminhão coletor de lixo comum, equipado com sistema de compactação e levantador de contêiner. O destino, tanto dos resíduos infectantes, após tratamento, como dos comuns, é um aterro sanitário localizado em Paulínia, licenciado pela Companhia Ambiental do Estado de São Paulo (CETESB).

Os materiais recicláveis são segregados; no entanto, devido ao pouco tempo de implementação da coleta seletiva, poucos são os pontos de segregação e a quantidade gerada. Os principais geradores de materiais recicláveis são os escritórios e os terminais de carga, sendo atualmente os únicos destinados a uma associação de cooperativas de Campinas, habilitada conforme o Decreto 5.940/2006.

Quanto aos resíduos classificados como Grupo B, ou seja, que representam risco químico, os mais representativos em aeroportos são óleos e materiais contaminados com tintas e óleos, lâmpadas de mercúrio e baterias chumbo-ácido inservíveis. Os óleos e materiais contaminados com os mesmos são gerados em caixas separadoras e nas oficinas de manutenção de veículos e empilhadeiras, respectivamente. Em ambos os casos, os serviços de remoção e destinação são realizados por empresas terceirizadas. O destino dos óleos é o reaproveitamento, enquanto que os demais resíduos contaminados, como estopas e embalagens, são destinados pela mesma empresa que recicla o óleo. Embora fiquem armazenadas em local fechado e de forma adequada, as lâmpadas de mercúrio, bem como as baterias chumbo-ácido e os pneus inservíveis são enviados para reciclagem em empresas especializadas em cada tipo de material. Entretanto, o tempo médio de armazenamento destes resíduos é superior a seis meses, aumentando a vulnerabilidade do local quanto aos riscos de contaminação do solo e da água.

Com relação aos resíduos de áreas verdes, o aeroporto realiza a disposição em área interna ao sítio aeroportuário, sem manejo prévio adequado, como trituração ou até mesmo compostagem. De maneira análoga, o aeroporto possui um antigo canteiro de obras com armazenamento de resíduos da construção civil. Contudo, em ambos os locais de bota-fora não há evidências de contaminação do solo. Vale ressaltar que, atualmente, os resíduos da construção civil gerados no aeroporto são destinados a usinas de reciclagem ou a outro destino conforme a Resolução do CONAMA 307/2002, e os que se encontram na área de bota-fora foram gerados antes da implementação do atual PGRS.

\section{Estratégias de manejo e monitoramento}

Os resultados gerados pela aplicação dos indicadores demonstram que 34\% deles apresentam avaliação ruim ou crítica. Com base no diagnóstico realizado no Aeroporto Internacional de Viracopos e utilizando-se o modelo de pressão-estado-resposta (OECD, 2001), foi possível identificar algumas estratégias de manejo e melhoria contínua para as não conformidades observadas nos indicadores com baixos índices. A pressão existente é relativa à geração, ao armazenamento, ao tratamento e à disposição dos resíduos sólidos no aeroporto. Assim, o estado relacionado às principais não conformidades corresponde às condições inadequadas de infraestrutura em áreas de armazenamento de resíduos, ao tempo de armazenamento de resíduos perigosos, à ausência de tratamento em zona primária e ao baixo percentual de materiais encaminhados para a reciclagem. Dessa forma, algumas estratégias de manejo, ou respostas, podem ser propostas:

- aumento dos pontos de segregação e coleta de materiais recicláveis;

- separação dos resíduos sólidos na fonte geradora;

- destino dos materiais recicláveis para associações ou cooperativas sem fins lucrativos;

- disposição em períodos inferiores a seis meses de baterias, lâmpadas e pneus inservíveis;

- armazenamento dos resíduos comuns e infectantes em ambientes diferentes;

- impermeabilização e construção de coberturas nos locais para armazenamento de resíduos;

- instalação e licenciamento de equipamento de tratamento de resíduos sólidos, como a autoclave;

- construção de uma estação de tratamento de resíduos sólidos;

- realização de compostagem dos resíduos de áreas verdes;

- impedimento da disposição de resíduos em áreas de bota-fora.

Embora algumas das medidas propostas estejam relacionadas às características estruturais do aeroporto, necessitando da realização de obras físicas, as mesmas não representam ações de grandes investimentos. Além disso, as ações propostas não requerem longos períodos de execução, podendo ser feitas em prazos inferiores há um ano, exceto as atividades contínuas, como a realização de tratamento de resíduos. Assim, impactos associados ao gerenciamento de resíduos sólidos podem ser corrigidos por uma administração aeroportuária mais eficiente em relação à gestão ambiental do Aeroporto Internacional de Viracopos.

Após a conclusão das medidas propostas, recomenda-se que os indicadores sejam aplicados novamente, contemplando um monitoramento ambiental periódico e proporcionando o controle eficaz da gestão dos resíduos gerados neste aeroporto. O monitoramento ambiental deve envolver essencialmente a coleta, a análise e a avaliação de dados ambientais para a orientação da melhor maneira de manejo ambiental ao local estudado. As técnicas a serem utilizadas devem estar embasadas em consultas à literatura e em debates com profissionais da área ambiental. Esse 
monitoramento poderá fornecer uma base de dados para o uso futuro, além de determinar se os objetivos das ações de manejo estão produzindo os resultados esperados sem alterar as características do ambiente.

Programas de educação ambiental também devem fazer parte da proposta de minimização dos impactos descritos neste estudo. Esses programas de educação ambiental podem despertar nas pessoas a conscientização dos valores dos ecossistemas encontrados, relacionando o gerenciamento de resíduos com o cotidiano. Para uma eficiência ainda maior, devem ser promovidas atividades educativas para funcionários e passageiros, sempre com o objetivo de demonstrar que, se bem aproveitados, conservados ou preservados, os recursos do meio ambiente trazem apenas benefícios para a comunidade.

\section{Conclusões}

Diversos aspectos e impactos negativos originados das atividades aeroportuárias estão relacionados ao mau gerenciamento de resíduos sólidos. Assim, por meio deste trabalho, foi possível desenvolver e aplicar uma metodologia para avaliação da gestão de resíduos sólidos em aeroportos de maneira a auxiliar a administração aeroportuária a identificar os aspectos ambientais significativos. A aplicação dos indicadores no Aeroporto Internacional de Viracopos obteve um desempenho de 2,9, em uma escala de um a cinco, caracterizando-o como regular. O uso dos indicadores associados ao modelo pressão-estado-resposta permitiu ainda a identificação de boas práticas e soluções ambientais para o gerenciamento de resíduos sólidos no Aeroporto Internacional de Viracopos. Portanto, foram propostas dez ações de resposta às pressões impostas ao meio ambiente, em decorrência dos resíduos gerados neste aeroporto. Complementarmente, por meio da metodologia proposta, é possível realizar análises comparativas entre aeroportos e acompanhar sistematicamente a evolução do desempenho no tema abordado. Esse monitoramento do desempenho por indicadores poderá fornecer, ao longo do tempo, uma base de dados para acompanhamento das ações realizadas, além de determinar se os objetivos das ações de manejo estão produzindo os resultados esperados.

Além disso, os indicadores e suas aplicações servem para auxiliar no planejamento e direcionamento de ações pela identificação de prioridades, sejam elas unidades aeroportuárias ou aspectos ambientais mais críticos. Com isso, podem-se definir as preferências em alocação de recursos, reduzir gastos e contribuir para a melhoria contínua do sistema de gestão ambiental de aeroportos. Como resultado, as ADAs podem ser divulgadas periodicamente, possibilitando às partes interessadas uma análise detalhada dos procedimentos e das medidas de controle ambiental adotados.

\section{Referências}

Associação Brasileira de Normas Técnicas - ABNT. (1996) Aeroportos gerenciamento de resíduos sólidos, NBR 8.843. Rio de Janeiro, 4 p.

Associação Brasileira de Normas Técnicas - ABNT. (2004) Gestão Ambiental - avaliação de desempenho - diretrizes, NBR 14.031. Rio de Janeiro, $38 \mathrm{p}$

BRASIL. (2010) Congresso Nacional. Lei $n^{\circ}$ 12.305, de 2 de agosto de 2010. Institui a Política Nacional de Resíduos Sólidos, Diário Oficial da União, Brasília.

BRASIL. (2006) Ministério da Agricultura, Pecuária e Abastecimento. Instrução Normativa $n^{\circ}$ 36, de 10 de novembro de 2006. Aprova o Manual de Procedimentos Operacionais da Vigilância Agropecuária Internacional. Diário Oficial da União, Brasília.

CAMPINAS. (2006) Lei Complementar no 15 de 27 de Dezembro de 2006. Dispõe sobre o Plano Diretor do Município de Campinas. Diário Oficial do Município de Campinas, Campinas.

CORDEIRO, E.; BARBOSA, C.B.;DUARTE, V.L. (2000) Gerenciamento de Resíduos Sólidos em Estações Aeroportuárias Brasileiras: Diagnóstico Situacional. In: XXVII Congresso Interamericano de Engenharia Sanitária e Ambiental, Anais..., ABES - Associação Brasileira de Engenharia Sanitária e Ambiental, Campinas.

INFRAERO - Empresa Brasileira de Infraestrutura Aeroportuária. (2011) Estatística dos Aeroportos. Brasília. Disponível em: <http:// www.infraero.gov.br/index.php/br/estatistica-dos-aeroportos.html> Acesso em: 21 jan. 2011.

OACI - Organização Internacional da Aviação Civil. (1996) Manual Guia de Proteção Ambiental para Aeroportos. Projeto PNUD OACI, RLA/92/031, Versão preliminar.

OECD - Organization for Economic Co-Operation and Development (2001) Environmental Indicators. OECD Publications, Paris, 155p.

PITT, M.; BROWN, A.; SMITH, A. (2002) Waste Management at Airports. Facilities, v. 20, p. 198-207.

REZENDE, D. \& MERLIN, S. (2003) Carbono social - agregando valores ao desenvo/vimento sustentável. Editora Peirópolis. Disponível em: <http:// www.socialcarbon.org/uploadDocs/Documents/Social_Carbon_book pt.pdf > . Acesso em: 24 jan. 2011.

SANTOS, C.K.N. (2008) Metodologia do Carbono Social - Manual do Multiplicador. Palmas: Instituto Ecológica.

STRUCHEL, A.; CAPPA, J.; BERNARDO, R. (2008) O Aeroporto Internacional de Viracopos na Revisão do Plano Diretor de Campinas SP em 2006. In: VII Simpósio de Transporte Aéreo, Sitraer, v. 7, p. 346-357.

WALM - Engenharia e Tecnologia Ambiental. (2008) EIA - Estudo de Impacto Ambiental: Ampliação do Aeroporto Internacional de Viracopos/ Campinas - SP, v. 1, p. 1.1-7.128, São Paulo. 